\title{
Effect of bio-calcium oxide on the morphology of hydroxyapatite
}

\author{
V. Rodríguez-Lugo ${ }^{1}$, C. Angeles ${ }^{2}$, A. de la Isla ${ }^{3}$, V.M. Castaño ${ }^{4} *$ \\ ${ }^{1}$ Universidad Autónoma del Estado de Hidalgo Area Académica de Ciencias de la Tierra y Materiales Carr. \\ Pachuca-Tulancingo km. 4.5, 42184 Pachuca, Hidalgo \\ ${ }^{2}$ Instituto Mexicano del Petróleo Coordinación de Investigación en Dúctos Eje Central Lázaro Cárdenas 152, 07730 México D.F \\ ${ }^{3}$ Universidad Autónoma de Querétaro Facultad de Ingeniería Campus Aeropuerto Santiago de Querétaro, Querétaro, México \\ ${ }^{4}$ Centro de Física Aplicada y Tecnología Avanzada Universidad Nacional Autónoma de México Boulevard Juriquilla 3001 \\ Santiago de Querétaro, Querétaro 76230, México \\ *Corresponding author E-mail: meneses@unam.mx
}

Copyright () 2015 V. Rodríguez-Lugo et al. This is an open access article distributed under the Creative Commons Attribution License, which permits unrestricted use, distribution, and reproduction in any medium, provided the original work is properly cited.

\begin{abstract}
A study of the Hydroxyapatite (HAp) synthesis through a hydrothermal process was carried out. Bio-Calcium oxide $(\mathrm{CaO})$ obtained by heat treatment of sand dollar was used in the synthesis at different proportions to react with monetite $\left(\mathrm{CaHPO}_{3}\right)$. Structural and chemical characterization of the samples was carried out using scanning electron microscopy (SEM), X-ray diffraction; Infrared spectroscopy (FTIR), and transmission electron microscopy (TEM). In each sample were observed different morphologies such as agglomerates, hexagonal particles, epitaxial growth, and fibers. O, Ca, $\mathrm{P}$, $\mathrm{C}$ and small amounts of $\mathrm{Mg}$ and $\mathrm{Si}$ were the main chemical components of the sharp morphologies. The hydroxyapatite, whitocklite, portlandite and calcite were the crystalline phases found in each of the samples analyzed. Two different growth shapes of HAp single crystals were found using transmission electron microscopy. The HAp single crystal with six well-defined prismatic faces was reveled to grow along side the $<10-10>$ crystallographic direction. The HAp single crystal with fiber morphology grew alongside c-axis. However, both morphologies of HAp single crystals present a ratio $\mathrm{Ca} / \mathrm{P}$ less compared with the stoichiometric ratio $(\mathrm{Ca} / \mathrm{P}=1.67)$.
\end{abstract}

Keywords: Biocalcium; Hydroxyapatite; Morphology; Biomaterlals; Microscopy

\section{Introduction}

Since Hydroxyapatite (HAp), a mineral with nominal composition Ca10 (PO4) 6 (OH) 2, is a major inorganic constituent of calcified tissue and it has also found to be a precursor for kidney stones, a great deal of effort has been dedicated to develop suitable methods for producing synthetic HAp [1-12], both from the point of view of the synthesis route (wet, solid state, sol-gel, etc.) and according to the chemical precursors utilized. Among the variety of synthesis approaches, the hydrothermal method enables to prepare well-crystallized, chemically-homogeneous, uniform and easyto-sinterize powders and also allows a relatively good control of the crystallites size. In fact, HAp crystals and nanocrystals have been produced by this method, even from low crystalline and irregular precursors [4], [5]. It has been reported that c-axis-elongated HAp single crystals can be successfully synthesized by the hydrothermal treatment of precipitated HAp. It is also known that the calcium concentration during the synthesis [1], [13], [14] has a direct effect on the homogeneity, composition, crystallinity, morphology and other features of the HAp crystal.

On the other hand, several chemical have been reported to be utilized for the synthesis of HAp. In particular, CaO is a common reactant in numerous solid-state reactions to yield different calcium carbonates [1], associated to monetite [2] or brushite [15] as a source of $\mathrm{P}$. What has been scarcely explored is the effect of bio- $\mathrm{CaO}$, that is, calcium oxide originated in living organisms.

Accordingly, we investigate here the effect of the bio-calcium oxide concentration during the heat treatment of a native Mexican sand dollar (mellita eduardobarrosoi sp. Nov.), which is a rich and natural source of calcium carbonate, that can be utilized as a low cost precursor for HAp [15-24], by using SEM, X-ray diffraction, FTIR, and TEM. 


\section{Experimental}

Samples with different calcium oxide concentration were prepared, as summarized in Table 1. As a source of PO4-3 monetite (CaHPO4) was employed. The synthesis was carried out by the hydrothermal method, using a Monel autoclave at a pressure of $6.5 \mathrm{MPa}$ at $270 \mathrm{oC}$ for 20 hours.

A low vacuum JEOL LV-5400SEM equipped with EDS was utilized. X-ray diffraction was performed in a Siemmens D-5000 apparatus equipped with a $\theta / 2 \theta$ goniometer and a graphite monochromator. X-ray were generated using a copper tube operating at $30 \mathrm{KeV}$ and $25 \mu \mathrm{A}$. The scan rate was $0.5 \mathrm{o} / \mathrm{sec}$ and data was collected every 0.02 degree and the scan was realized at $5^{\circ}-70^{\circ}$. A 550 NICOLET FTIR spectrometer in the medium infrared region was also used on samples mixed with $\mathrm{KBr}(1: 10)$. A JEOL-2010 TEM at $200 \mathrm{KeV}$, with nominal resolution of $0.2 \mathrm{~nm}$ and equipped with EDS analysis, was utilized, as well.

\section{Results and discussion}

A low magnification micrograph of the general morphology of sample $\mathrm{HCaO} 201$ can be observed in Figure 1a, whereas Figure $1 \mathrm{~b}$ corresponds to sample $\mathrm{HCa} 20652$, two samples with a different nominal $\mathrm{CaO}$ content but where, in both cases, the CaHPO4 nominal content was equivalent or higher to that of $\mathrm{CaO}$ (see Table 1). As observed in the micrographs and in Table 2, which summarized the results of the EDS analysis of different regions of each sample, not only the chemical composition changes, both over all the sample and locally, with the $\mathrm{CaO}$ relative content, but also the microsctructure.

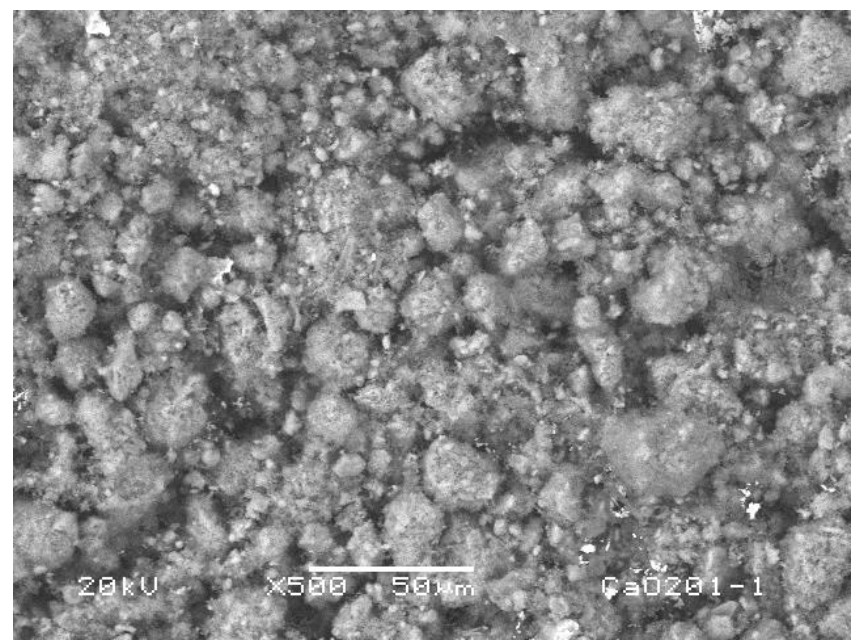

A

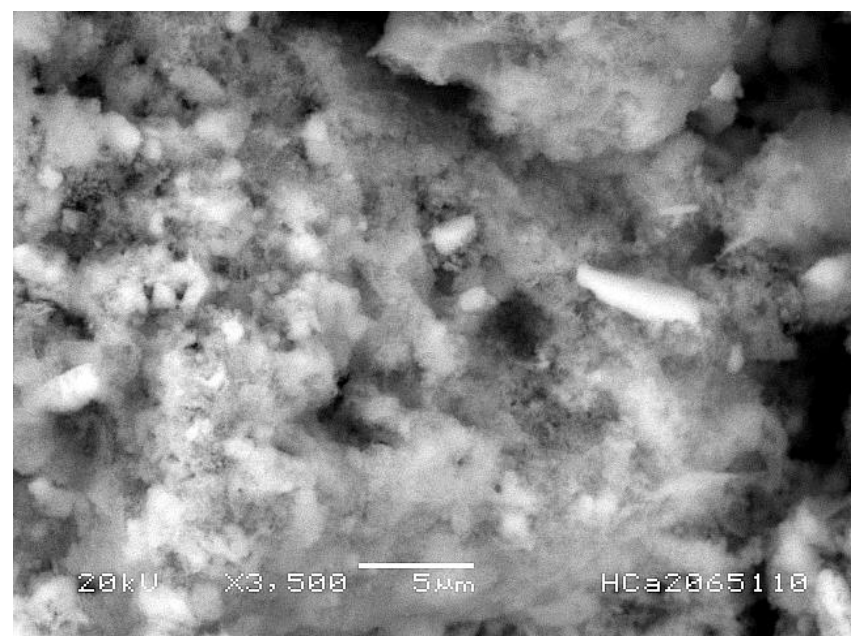

$\mathrm{C}$

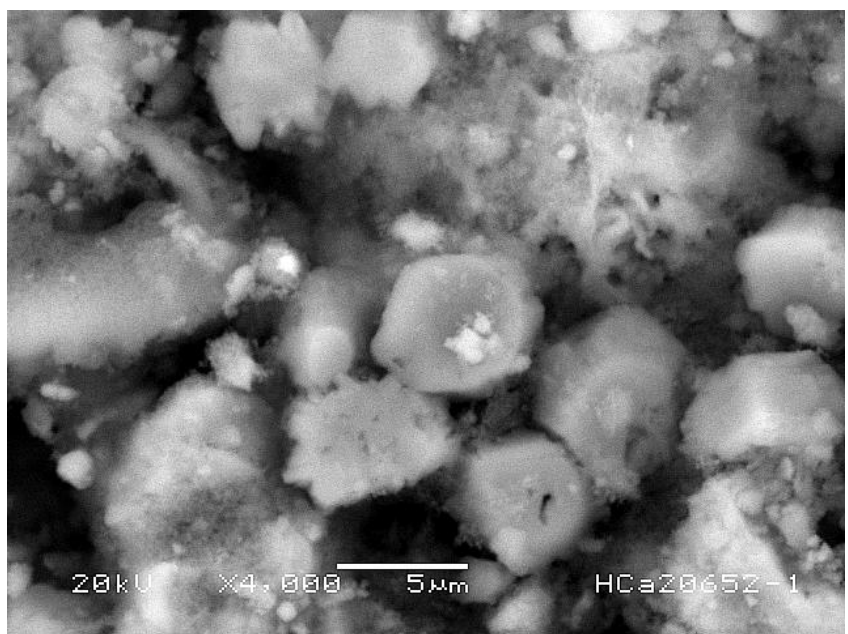

B

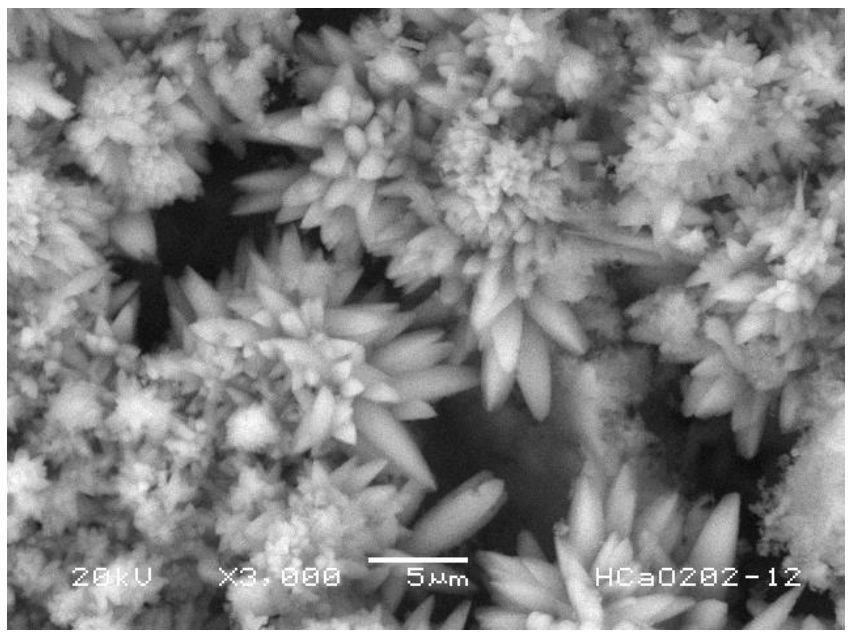

D 


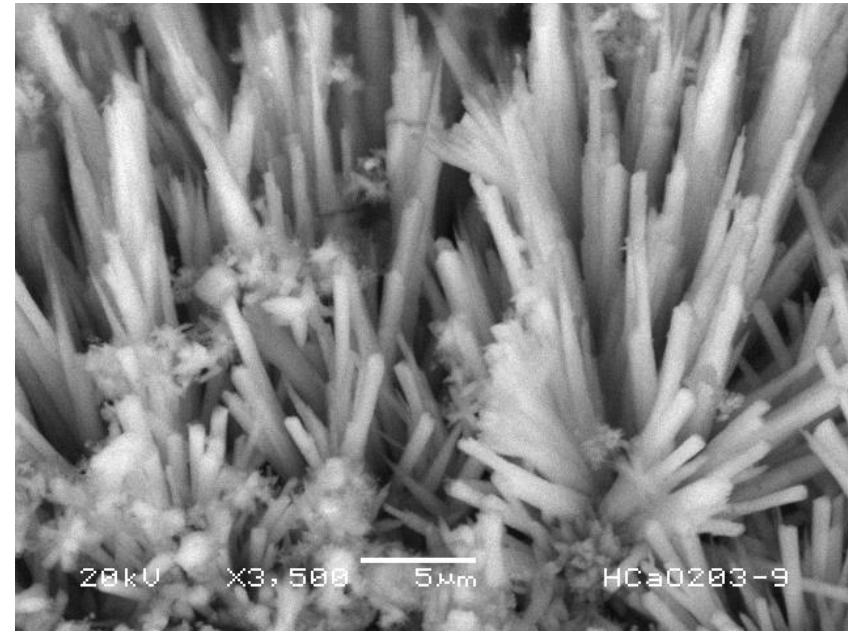

$\mathrm{E}$

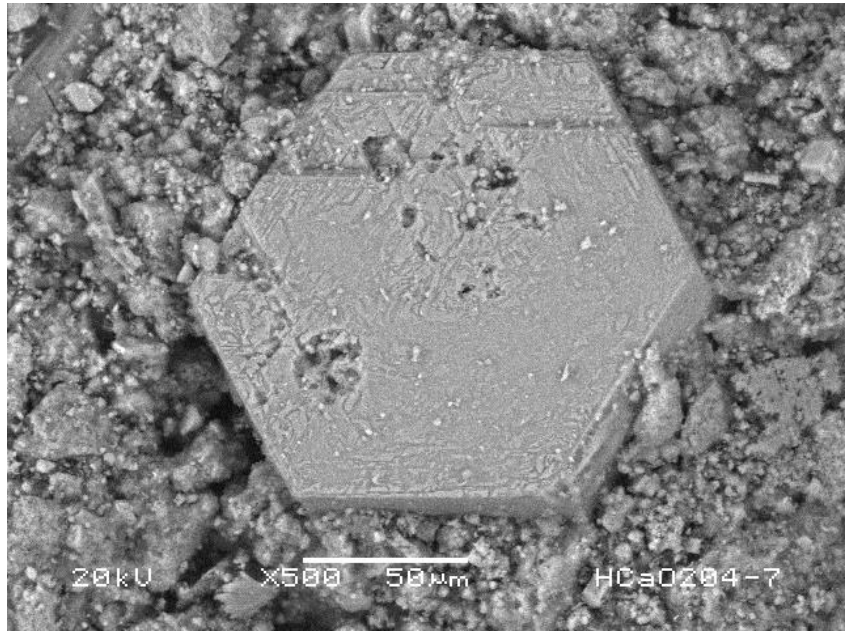

$\mathrm{F}$

Fig. 1: SEM Micrographs of (See Table 1): A) Hcao201, B) Hca20652, C) Hcao202, D) Hcao203, E) and F) Hcao204

Table 1: Composition of the Samples

\begin{tabular}{llllll}
\hline Sample & $\mathrm{CaO}(\mathrm{gr})$ & $\mathrm{CaHPO} 4(\mathrm{gr})$ & Temperature $(\mathrm{oC})$ & Pressure $(\mathrm{Mpa})$ & Time(hr) \\
\hline $\mathrm{HCa} 20651$ & 1.0 & 3.63 & 270 & 6.5 & 20 \\
$\mathrm{HCaO} 201$ & 0.5 & 1.0 & 270 & 6.5 & 20 \\
$\mathrm{HCa} 20652$ & 1.0 & 1.0 & 270 & 6.5 & 20 \\
$\mathrm{HCaO} 202$ & 1.5 & 1.0 & 270 & 6.5 & 20 \\
$\mathrm{HCaO} 203$ & 2.0 & 1.0 & 270 & 6.5 & 20 \\
$\mathrm{HCaO} 204$ & 2.5 & 1.0 & 270 & 6.5 & 20 \\
\hline
\end{tabular}

Flat particles, of around $5 \mu \mathrm{m}$ that had a laminar shape were observed in the image and agglomerates of different sizes, these particles present a considerable decrease in the phosphorous contain and an increase in the carbon contain observed by the EDS as shown in table 2. Figure 1c shows an amplification of the agglomerates where we observed small fibers not well defined at this amplification with an increase in the phosphorous contain. The table 2 shows the chemical composition of each of the observed morphologies in the samples. The SEM micrograph of the figure 1d shows that the agglomerates of the sample $\mathrm{HCaO} 202$ are conformed by small crystals with an epitaxial growth. This growth type is confirmed by a rombohedral structure that has a length of $7.42 \mu \mathrm{m}$ and $0.64 \mu \mathrm{m}$ diameter. The chemical composition obtained by ED's shows that the crystals have no phosphorous but a great amount of O and Ca. In the SEM micrography of the sample $\mathrm{HCaO} 203$ figure 1e we observed agglomerated formation similar to the agglomerated found in sample $\mathrm{HCaO} 202$ and also others with similar morphology but with a greater length, which has a size of $0.95 \mu \mathrm{m}$ of diameter and $7.14 \mu \mathrm{m}$ of length. It has a similar chemical composition found in the crystals sample $\mathrm{HCaO} 202$. However, the sample identified as $\mathrm{HCaO} 204$, in addition to the agglomerates described, presents another different feature. We observed great particles with hexagonal shape whose size is of approximately $16.30 \mu \mathrm{m}$, the SEM micrography is illustrated in the figure $1 \mathrm{f}$. The principal chemical components obtained by EDS are O and Ca see table 2.

The crystalline phases in each of the samples were determinate by X-ray diffraction. Spectrum of each sample is illustrated in figure 2. Figure 2a shows the spectrum that corresponds to the sample HCa20651. It has a stoichiometric composition and therefore the spectrum only shows the presence of HAp and whitlockite, however, we observed that the presence of hydroxyapatite phase is in all samples, see the spectrums of the figure 2. Moreover is important to mention that the whitlockite phase only was detected in the samples whose calcium oxide concentration is near to the stoichiometric composition (only HCa201). Other important features observed in the figure 2 are the characteristic peaks of monetite and calcite appearing in the spectrum of the figures $2 \mathrm{~b}$ to $2 \mathrm{f}$. Peaks are not observed in the spectrum of the figure $2 \mathrm{a}$. Figure $2 \mathrm{~d}$ shows, in addition to characteristic peaks of HAp, monetite and calcite phase, a very intense peak appearing at 18.5 degree in $2 \theta$ and is present in the $\mathrm{HCa} 202, \mathrm{HCa} 203$ and $\mathrm{HCa} 204$ samples. This peak is characteristic of the portlandite cubic phase and can be observed in the spectrum from the figures $2 \mathrm{~d}$ to $2 \mathrm{f}$. 
Table 2: Elemental Analysis of Different Regions in Each Sample

\begin{tabular}{|c|c|c|c|c|c|c|c|c|}
\hline \multirow{2}{*}{ SAMPLE } & & \multicolumn{7}{|c|}{ Element } \\
\hline & & $\mathrm{O}$ & $\mathrm{C}$ & $\mathrm{Mg}$ & Sí & $\mathrm{Al}$ & $\mathrm{P}$ & $\mathrm{Ca}$ \\
\hline \multirow{2}{*}{ HCa20651 } & General & 40.10 & 13.11 & 0.58 & & & 9.47 & 36.74 \\
\hline & Agglomerate & 38.65 & 12.44 & 0.63 & & & 14.06 & 34.22 \\
\hline \multirow{3}{*}{$\mathrm{HCaO} 201$} & $\begin{array}{l}\text { Not including } \\
\mathrm{C}\end{array}$ & 53.70 & & 1.27 & & & 14.53 & 30.52 \\
\hline & Including C & 45.09 & 6.37 & 1.32 & & & 14.26 & 32.97 \\
\hline & General & 51.99 & 9.81 & 3.17 & 0.51 & & 11.32 & 23.38 \\
\hline \multirow{3}{*}{$\mathrm{HCa} 20652$} & Particles & 52.81 & 13.49 & 2.74 & 0.29 & & 2.96 & 27.71 \\
\hline & Agglomerate & 50.75 & 9.99 & 1.99 & 0.32 & & 13.99 & 22.95 \\
\hline & Agglomerate & 38.65 & 12.44 & 0.63 & & & 14.06 & 34.22 \\
\hline \multirow{5}{*}{$\mathrm{HCaO} 202$} & General & 59.51 & 11.71 & 2.35 & & & 1.84 & 29.58 \\
\hline & Agglomerate & 50.12 & 10.77 & 2.47 & & & 9.70 & 26.93 \\
\hline & Crystallites & 52.30 & 13.44 & 1.56 & & & 0.65 & 32.05 \\
\hline & General & 53.46 & 11.61 & 3.78 & & & 3.01 & 28.14 \\
\hline & Agglomerate & 53.10 & 10.71 & 3.43 & & & 2.18 & 30.59 \\
\hline \multirow{2}{*}{$\mathrm{HCaO} 203$} & Particles & 54.45 & 6.62 & 1.74 & & & 0.45 & 36.73 \\
\hline & Crystals & 55.64 & 15.39 & 0.98 & & & 0.236 & 27.75 \\
\hline \multirow{3}{*}{$\mathrm{HCaO} 204$} & General & 52.60 & 8.13 & 4.41 & 0.34 & 0.56 & 6.70 & 27.25 \\
\hline & Particles & 62.10 & 8.23 & 5.06 & 0.39 & 0.38 & 2.62 & 21.22 \\
\hline & Crystallites & 56.04 & 5.81 & 0.73 & & & 0.40 & 37.02 \\
\hline
\end{tabular}

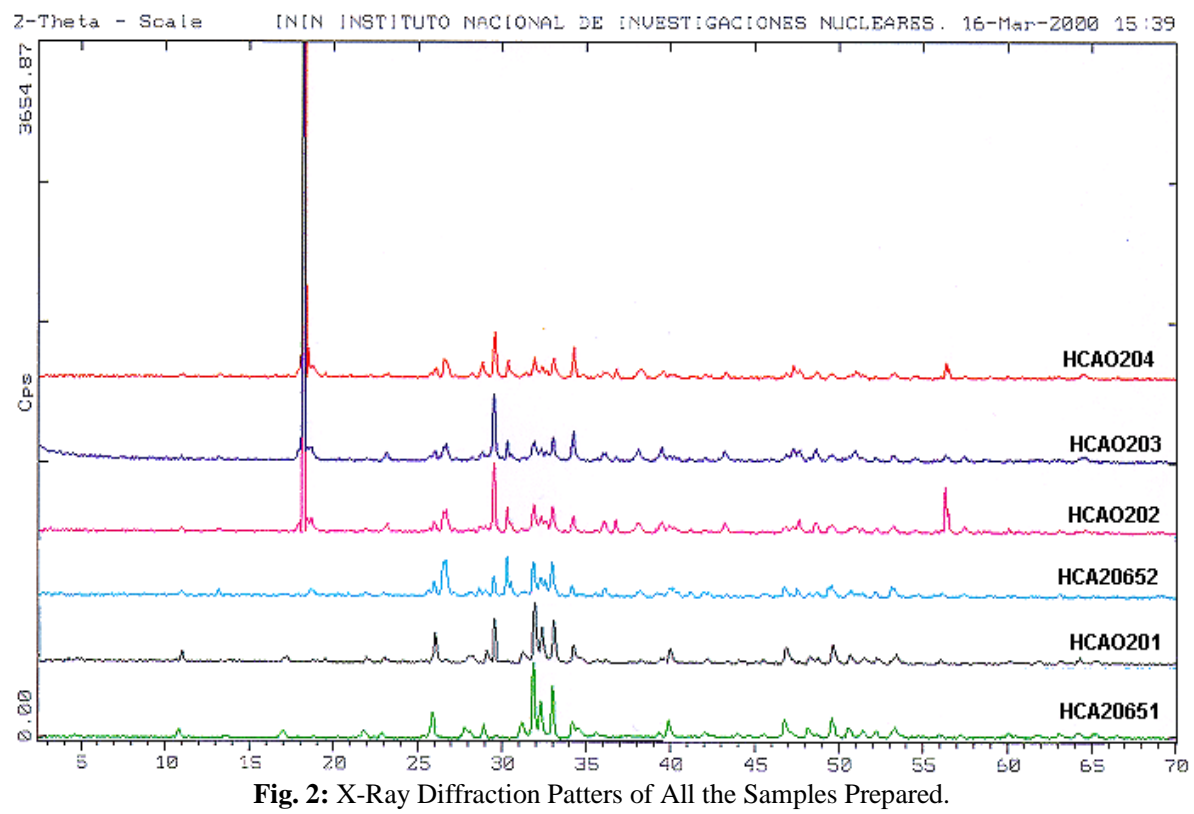

The FTIR spectrum of the samples is shown in figure 3. We observed the formation of new bands when the CaO concentration is increased. The absorption bands that correspond to the carbonates (CO32-) are localized between 1470 $\mathrm{cm}-1$ and $1450 \mathrm{~cm}-1,870-874 \mathrm{~cm}-1$. A new absorption band appears at $1406 \mathrm{~cm}-1$ indicating the substitution of carbonates by PO43- ions in the structure. This is illustrated in the figure 3c. The apparition of bands at 1041-1045 cm1, 1094-1103 cm-1, 603-609 cm-1, 567-568 cm-1, 446- $473 \mathrm{~cm}-1$ allow to determinate the presence of PO43- ions of the apatite. Moreover, the observed bands at 3430-3447 cm-1 and 1633-1637 cm-1 correspond to the vibration modes of bond $\mathrm{O}-\mathrm{H}$ and are characteristic of the water. The bands that appear at $3568-3696 \mathrm{~cm}-1$ and $636 \mathrm{~cm}-1$ belong to the hydroxyl groups $\mathrm{OH}-1$. As can be observed the peak in this band is increased, as it is the calcium oxide concentration. The presence and increase of this band is directly related with the increase of the calcium hydroxide (portlandite) in the samples. Its presence is detected since the sample HCa201, which indicate that this phase is present in small amount and cannot be detected by X-ray diffraction. 


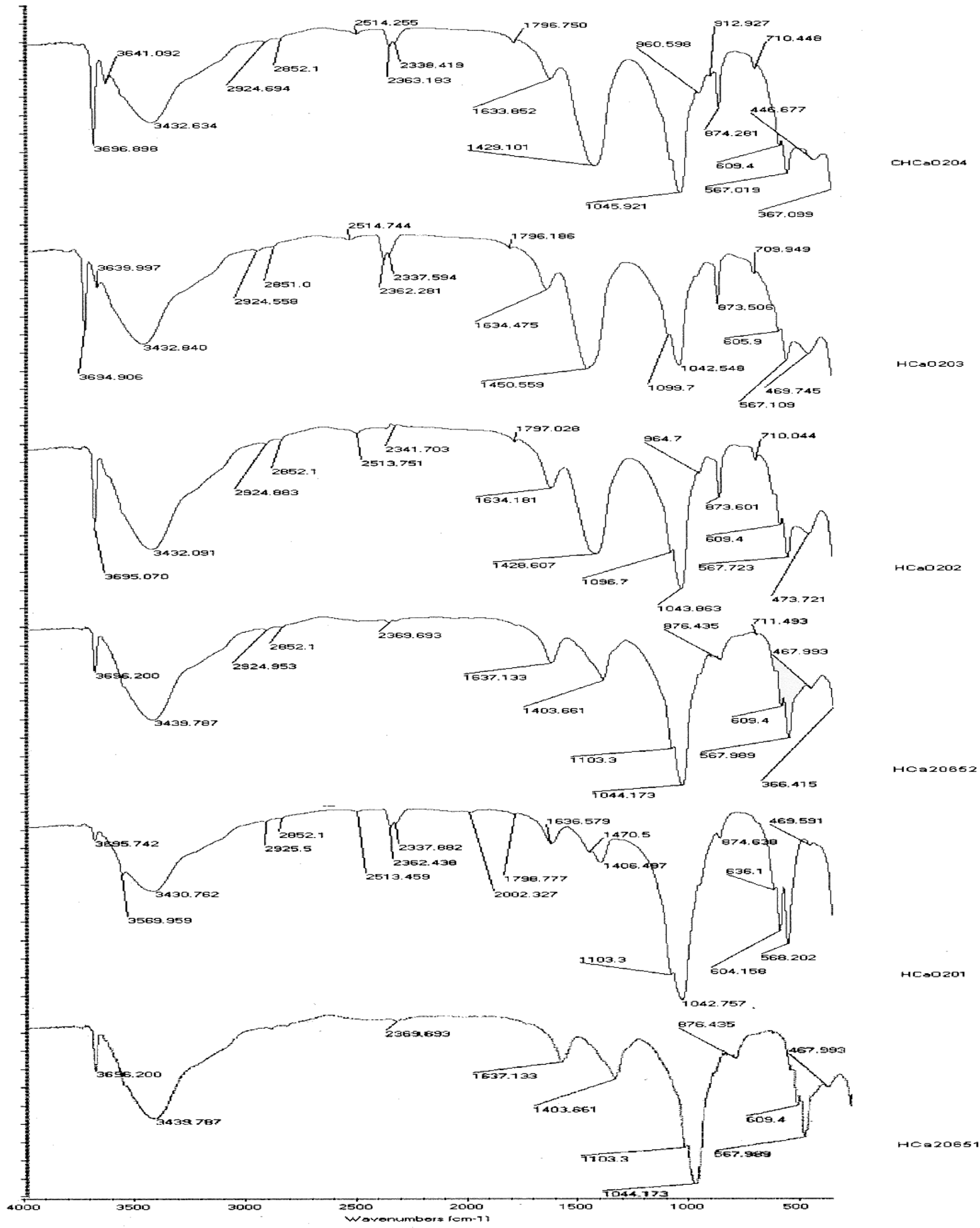

Fig. 3: IR Spectra of All the Samples Prepared.

The results obtained by transmission electron microscope show that the HAp single crystal observed in the sample $\mathrm{HCa} 20651$ grows in two different morphologies. However, the number of morphologies in the samples changes when the calcium oxide concentration is increased. For instance, the samples with a calcium oxide concentration near to the stoichiometric composition ( $\mathrm{HCaO} 201)$ had two different morphologies: hexagonal and fibers, both as single crystal. The sizes of these morphologies are varied. The fibers for example, can be found in different length and thickness. In the samples whose calcium oxide concentration is more elevated ( $\mathrm{HCaO} 204)$, we only found HAp fibers with thinner thickness. Figure 4 shows the typical morphologies found in the samples, in the figure $4 \mathrm{a}$ it can be observed a morphology of six well-defined prismatic face. Every side has a nearly size $77 \mathrm{~nm}$. In the case of the figures $4 \mathrm{~b}$ and $4 \mathrm{c}$ are illustrated two fibers that have different thickness and length. The first fiber has a length of $750 \mathrm{~nm}$ and thickness of $150 \mathrm{~nm}$ and the second fiber has a length of $1200 \mathrm{~nm}$ and thickness of $30 \mathrm{~nm}$. As can be observed there is a great difference on the thickness in both fibers. The analysis of the electron diffraction patterns can generally indicate the growth direction of the crystal. 


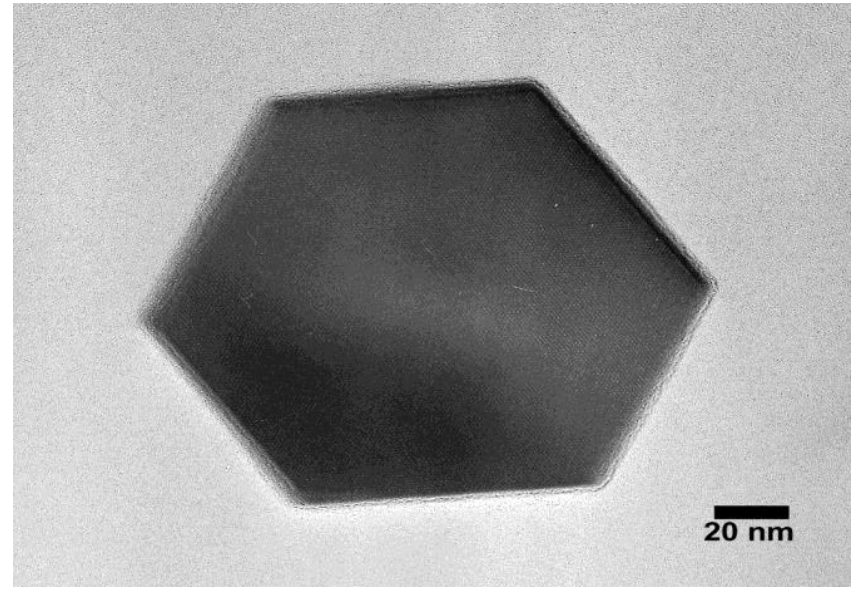

A

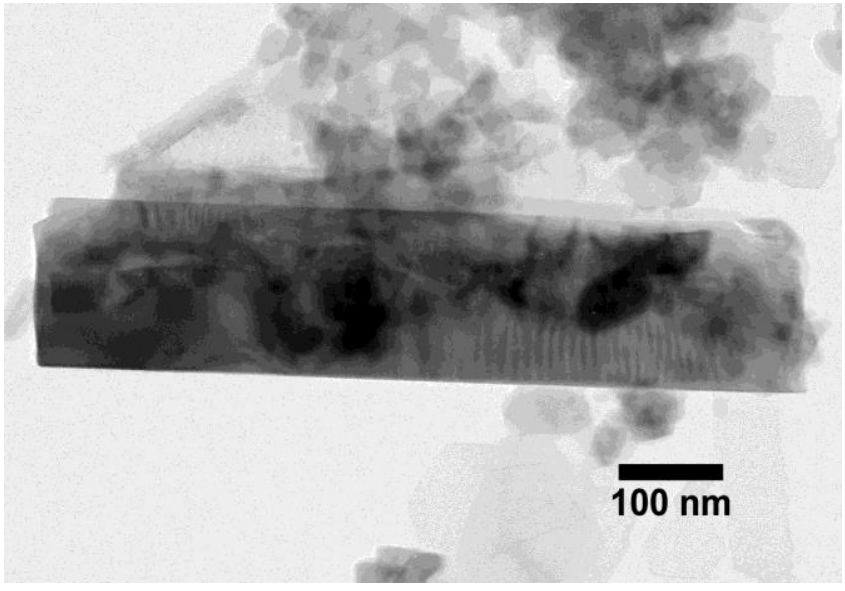

B

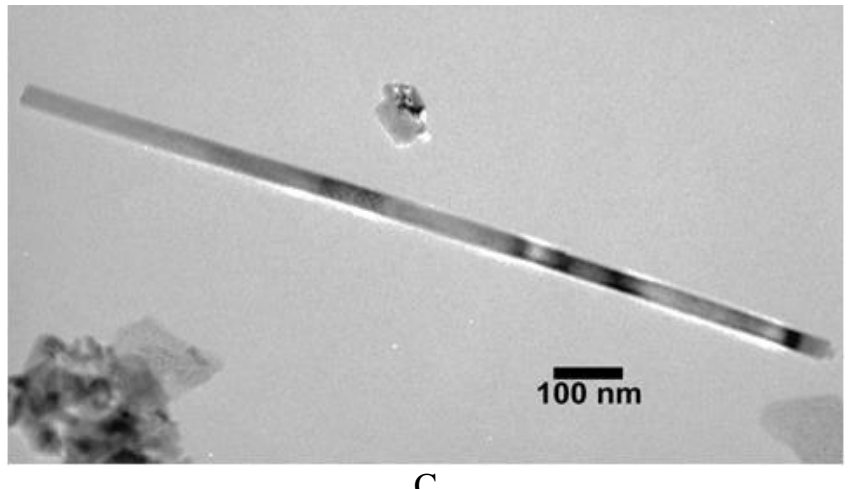

$\mathrm{C}$

Fig. 4: Bright Field Image Illustrating the Morphological Characteristic of the Hydroxyapatite Single Crystal. A) Single Crystal with A Six WellDefined Prismatic Faces, B) and C) Single Crystal with Fiber Morphology.

A typical electron diffraction pattern was obtained of the single crystals of six well-defined prismatic faces. It is illustrated in the figure 5. The analysis of the pattern indicates that was observed in the [0001] direction. The morphologies and the zone axis of these crystals suggest that they grew alongside $<10-10>$ directions. Moreover, figure 6 shows three typical electron diffraction patterns of the fibers. The analysis of the patterns indicates that were observed in the faces of the hexagonal prism. For instance, the pattern of the figure 6a was observed in the [ $11-100]$ direction and the figure $6 \mathrm{~b}$ was observed in the $\left[\begin{array}{llll}-1 & 1 & 0 & 0\end{array}\right]$ direction. It can be observed that the directions belong to the faces of the hexagonal prism. However, the forms of the electron diffraction patterns are different. These results can suggest that crystal face of the hexagonal prism have different ionic groups. In the other hand, the intensity of the 002 plane in all the patterns of the figure 6 clearly shows that the growth direction of the HAp fibers was along side of the crystallographic c-axis. Chemical analysis carried out in the HAp single crystals on the two different morphologies is shown in the figure 7 . The image shows a typical X-ray energy spectrum illustrating the principal chemical elements of a fiber. The chemical composition in the HAp single crystal of the two different morphologies shows a deficiency in the calcium contain because the atomic ratio $\mathrm{Ca} / \mathrm{P}$ is less compared to the atomic ration stoichiometric $(\mathrm{Ca} / \mathrm{P}=1.62)$. The ration $\mathrm{Ca} / \mathrm{P}$ obtained in HAp single crystals with hexagonal morphology is 1.5 while HAp single crystal with fiber morphology is 1.4. It is important to mention that this value is the media value of all analysis realized over each of the crystalline morphologies. This deficiency of $\mathrm{Ca}$ in the HAp structure can have an effect in the diffraction phenomena and could explain these electron diffraction patterns obtained on the prismatic face too [25].

\section{Conclusions}

The growth of HAp whith different concentration of calcium oxide as a precursor was obtained. The conditions used in the hydroxyapatite synthesis allow to obtain different morphologies, and chemical composition and therefore several crystalline phases in each sample. The $\mathrm{CaO}$ concentrations play a very important rule on the hydroxyapatite morphology and the growth direction. These results clearly show that the growth directions were respectively the $<10-1$ 0> and [0001] directions on both morphologies (hexagonal and fibbers). However, is important to point out that the chemical analyses of these single crystalline structures presents a deficient calcium contain. 


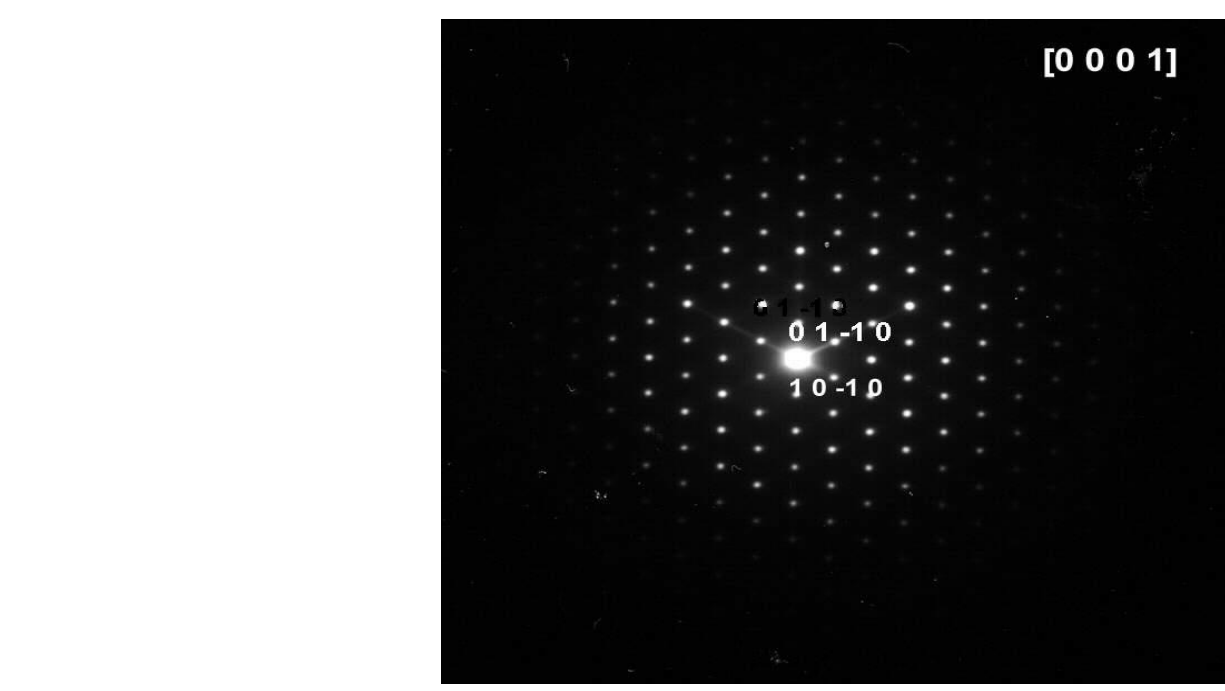

Fig. 5: Electron Diffraction Pattern from the Crystallite of the Figure 4a. the Zone Axis Is $\left[\begin{array}{llll}0 & 0 & 0 & 1\end{array}\right]$.

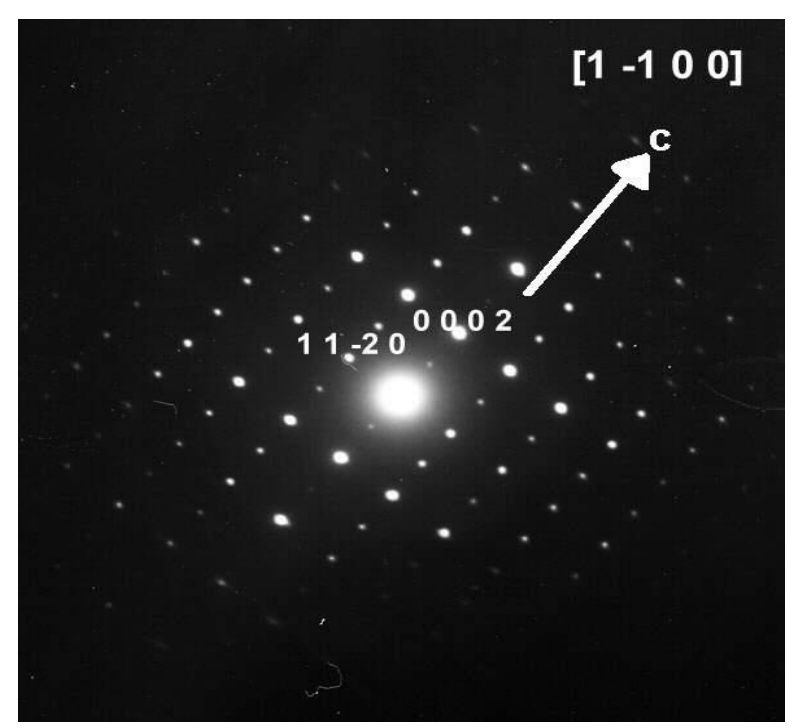

A

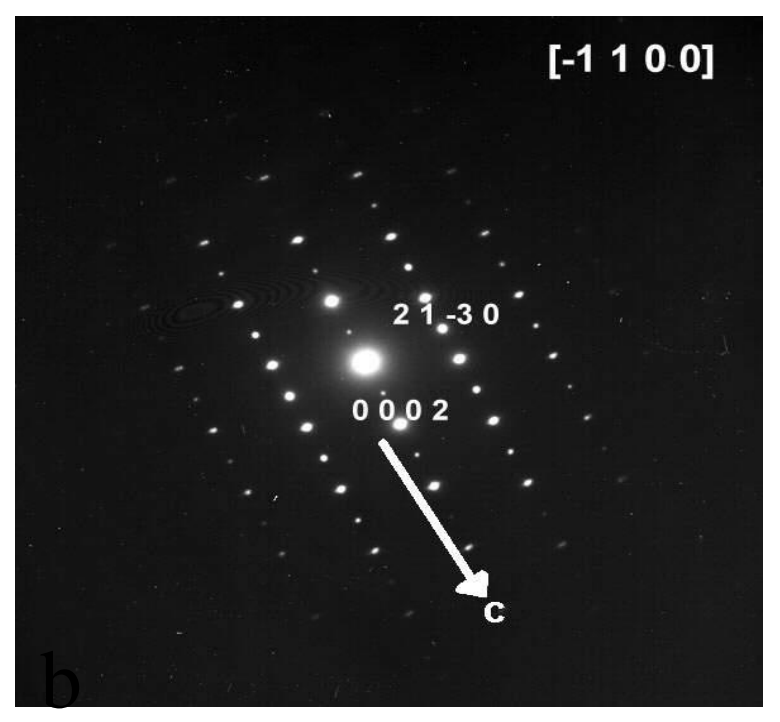

B

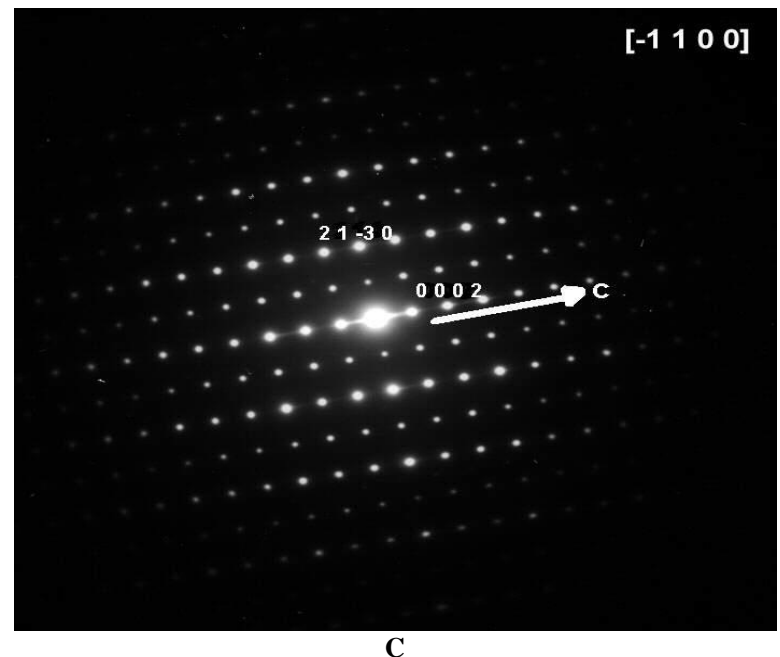

C

Fig. 6: Electron Diffraction Patterns Obtained of the Fibers. The Zone Axis Is A) $\left[\begin{array}{llll}1 & -1 & 0 & 0\end{array}\right]$, B) and C) [ $\left[\begin{array}{lll}-1 & -1 & 0\end{array}\right]$. The Directions Correspond to the Prismatic Face. 


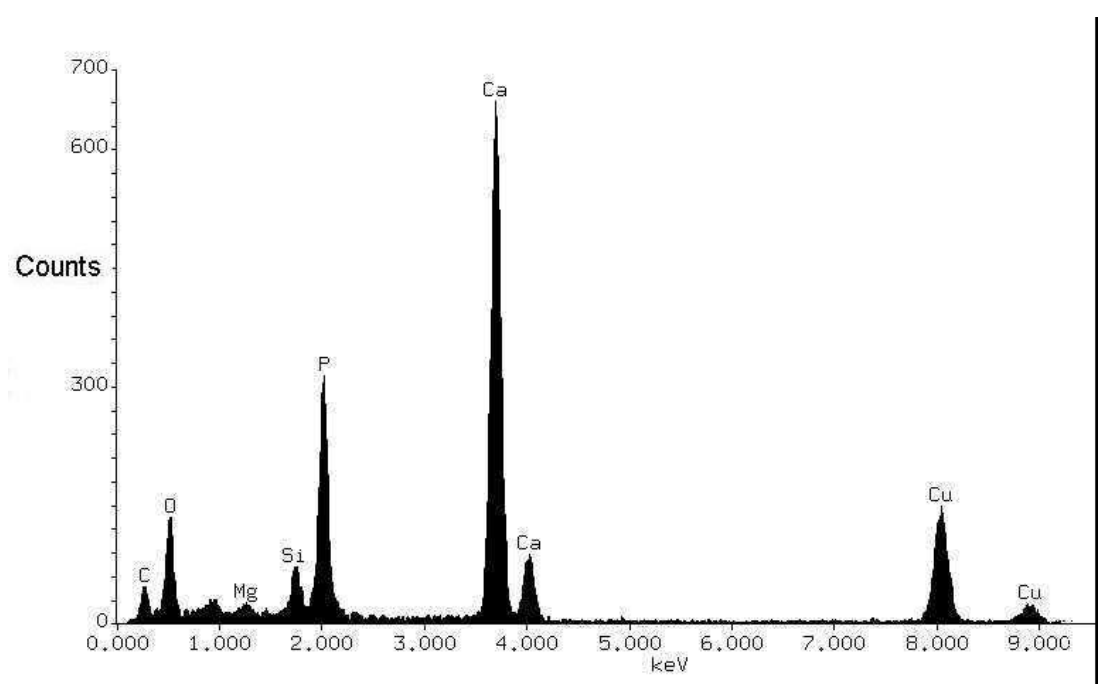

Fig. 7: X-Ray Energy Dispersive Spectrum Showing the Principal Elements that Has Hap Single Crystal.

\section{Acknowledgements}

The authors appreciate the financial support provided by the project "Sintésis y caracterización de apatita a través de procesos hidrotermales", PROMEP - UAEH - PTC - 6669.

\section{References}

[1] Skinner, H. C. W; Phases relations in the CaO-P2O5-H2O system from $300^{\circ} \mathrm{C}$ to $600^{\circ} \mathrm{C}$ at $2 \mathrm{kB} \mathrm{H} 2 \mathrm{O}$ pressure, Am. J. Science 273,545 (1973). http://dx.doi.org/10.2475/ajs.273.7.545.

[2] De Maeyer, Erna A., Ronald M. H. Verbeck, and Didier E. Naessens; Optimization of preparation of Na+ and containing hydroxyapatite by the hydrolysis of monetite, J. Crystal Growth, 135, 539 (1994). http://dx.doi.org/10.1016/0022-0248(94)90145-7.

[3] Yoshimura Masahiro, Hiroyuki Suda; Hydrothermal synthesis of biocompatible whiskers, J. Mater. Sci. 29, 3399 (1994). http://dx.doi.org/10.1007/BF00352039.

[4] Yasukawa Akemi, Satoshi Ouchi, Kazuhiko Kandori and Tatsuo Ishikawa; Preparation and characterization of magnesium- calcium hydroxylapatites, J. Mater. Chem., 6, 1401 (1996). http://dx.doi.org/10.1039/jm9960601401.

[5] Nicolopoulos, J. L.; M. Gonzales-Calbet; M. P. Alonso, M. T. Gutierrez-Rios, M. I. de Frutos, and M. Vallet- Regi; Characterization by TEM of local crystalline changes during irradiation damage of hydroxyapatite compound, J. Solid State Chem. 116, 265 (1995).

[6] Yubao L., C. P. A. T. Klein, J. De Wijn, S. Van de Meer; Shape change and phase transition of needle-like non-stoichiometric apatite crystals, J. Mater. Sci.: Mater. In Med. 5, 263 (1994). http://dx.doi.org/10.1007/BF00122395.

[7] Abbona Francesco, Alain Baronnet; A XRD and TEM study on the transformation of amorphous calcium phosphate in the presence of magnesium, J. Cryst. 165, 98 (1996). http://dx.doi.org/10.1016/0022-0248(96)00156-X.

[8] Saenz, M.L. Montero, G. Mondragón, V. Rodríguez and V.M. Castaño, "Effect of pH on the precipitation of hydroxyapatite on silica gel", Materials Research Innovations 7, 68(2003).

[9] Recillas, S.; G. Mondragón, V. Rodríguez y V. M. Castaño, "Growth of calcium phosphates onto chemical-functionallized cottons", Designed monomers and Polymers, 6, 383 (2003). http://dx.doi.org/10.1163/156855503771816840.

[10] Recillas, S.; J. A. Asecencio, V. Rodríguez-Lugo and V. M. Castaño, "Molecular Simulation of Reactivity of Chemically-Fuctionalized Nonocellulose", Nano Treds: A Journal of Nanotechnology and us Applications, 2 Issue 2, 5(2009).

[11] Recillas, S.; V. Rodríguez-Lugo, M. L. Montero, S. Viquez-Cano, L. Hernández and V. M. Castaño, "Studies on the precipitation behavior of calcium phosphate solutions". Journal of Ceramic Processing Research, 13 No. 1, 5(2012).

[12] Rodriguez-Lugo, V; D. Mendoza-Anaya and R. F. Estrada, "Biomimetic Growth of Hydroxyapatita on Collagen", revista electrónica ideas CONCYTEG 7, 87(2012),

[13] Brown, Paul; Phase relationships in the ternary system CaO-P2O5-H2O at $25^{\circ} \mathrm{C}$, J. Am. Ceram. Soc. 75 , 17 (1992). http://dx.doi.org/10.1111/j.1151-2916.1992.tb05435.x.

[14] Skinner, H. C. W; Phases relations in the CaO-P2O5-H2O system from $300^{\circ} \mathrm{C}$ to $600 \square \mathrm{C}$ at $2 \mathrm{kB} \mathrm{H} 2 \mathrm{O}$ pressure, Am. J. Sci. 273 , 545 (1973). http://dx.doi.org/10.2475/ajs.273.7.545.

[15] Yeong, B., Junmin, X and Wang, J., Mechanochemical Synthesis of Hydroxyapatite from Calcium Oxide and Brushite, J. Amer. Ceram. Soc. 84, 465 (2001) http://dx.doi.org/10.1111/j.1151-2916.2001.tb00681.x.

[16] Ascencio J. A., V. Rodríguez-Lugo, C. Angeles, T. Santamaría and V. M. Castaño; Theoretical Analysis of hydroxyapatite and its main precursors by quantum mechanics and HREM image simulation, Comp. Mater. Sci. 25, 413 (2002) http://dx.doi.org/10.1016/S0927$\underline{0256(02) 00243-4}$.

[17] Rodríguez-Lugo, V.; G. A Camacho- Bragado; R., Cruz-Colin and V. M. Castaño, Synthesis of hydroxyapatite by hydrotermal process, V Interamerican Electron Microscopy Congress, Materials|Works|95.htm, (1999).

[18] Rodríguez-Lugo, V., G. A Camacho- Bragado, C. Angeles- Chávez, R., Cruz-Colin and V. M. Castaño, Morphological and compositional Changes on sand dollar induced by heat treatments, Mater. \& Manuf. Proc. 18, 67 (2003) http://dx.doi.org/10.1081/AMP-120017589.

[19] Rodriguez-Lugo, V.; J. A. Ascencio, C. Angeles- Chavez, A. Camacho- Bragado and V. M. Castaño; Controlled Hydrothermal Production of Hydroxylapatite from a marine skeleton, Mater. Technol. 16, 97 (2001)

[20] Rodríguez-Lugo, V.;M. Hernández and C. Angeles-Chavez, Synthesis of hydroxylapatite from san dollar and $\beta$-tricalcium phosphate by the solid-state method, Materials and Manufacturing proceses, 18, 6, 903 (2003).

[21] Fernández, M. E.; C. Angeles Ch., G. Mondragón-Galicia and V. Rodríguez-Lugo, "TEM and Molecular Simulations studies on the hydroxylapatite structure with Si and Mg Impurities", Journal of materials Science: Materials in mediciene, 15, 6, 735 (2004). 
[22] Rodríguez-Lugo, V.: C. Angeles-Chavez, G. Mondragon, S. Recillas-Gispert and V.M.Castaño, "Synthesis and structural characterization of hydroxylapatite obtained from $\mathrm{CaO}$ by hydrothermal metod", Materials Research Innovations, 9, 157 (2005).

[23] Rodríguez-Lugo, V.; J. Sánchez Hernández, M. J. Arellano- Jiménez, P. H. Hernández-Tejeda and, S. Recillas-Gispert, "Characterization of Hidroxiapatita by Electron Microscopy”, Microscopy and Micoanalysis, 11, 6 (2005). http://dx.doi.org/10.1017/S1431927605050762.

[24] Cui F. Z., L. F. Zhou, H. Cui, C. L. Ma, H. B. Lu, H. D. Li; Phase diagram for controlled crystallization of calcium phosphate under acid organic monolayers, J. Cryst. 169, 557 (1996). http://dx.doi.org/10.1016/S0022-0248(96)00405-8.

[25] Acosta, L. Mendieta, I., Núñez, R., Cajero and V.M. Castaño, V.M. Int. J. Nanomedicine 7, 4777 (2012). 